Published by Al-Nahrain College of Medicine P-ISSN 1681-6579

E-ISSN 2224-4719

Email: iraqijms@colmed-alnahrain.edu.iq

http://www.colmed-alnahrain.edu.iq

http://www.iraqijms.net

Iraqi JMS 2018; Vol. 16(2)

\title{
The Value of Magnetic Resonance Imaging in the Evaluation of Peri-Anal Fistula
}

\author{
Ammar M. Jawad ${ }^{1}$ FIBMS (Rad.), Mohammed A. kadhim ${ }^{1}$ FIBMS (Rad.), Zainab K. Al-Jobouri² \\ FIBMS, Mohssin A.A. Hussain² MRI application specialist
}

\begin{abstract}
${ }^{1}$ Dept. of Surgery, College of Medicine, Al-Nahrain University, Baghdad, Iraq, ${ }^{2} \mathrm{Al}-$ Imamein Al-Kadhimein Medical City, Baghdad, Iraq
\end{abstract}

\begin{abstract}
Background Perianal fistula accounts for $0.01 \%$ of general population and is frequently managed inadequately resulting in a significant morbidity. Magnetic resonance imaging (MRI) plays an essential role in the preoperative assessment of the disease, therefore improving post-operative surgical outcome.

Objective To study the role of MRI in the evaluation of perianal fistula and to show the value of using contrast enhanced MR study in the determination of the precise tract pathway, extensions and other associated pathologies.

Methods A cross sectional analytic study was conducted on a total of 32 patients with perianal fistulas in the MRI Department of Al-Imamein Al-Kadhimein Medical City, Baghdad, Iraq during the period from November 2015 to December 2016. Patients underwent MRI examination using axial and coronal T2 weighted images with and without fat suppression and T1 fat suppressed sequences before and after contrast administration. The type of fistula, location of the internal opening, associated abscesses and/or sinus tracts and horseshoe extension were evaluated using different MR sequences.

Results The most common type of fistula encountered was the inter-sphincteric type, which was seen in 21 patients (66\%), of those patients 16 fistulas (50\%) were grade I and 5 fistulas (16\%) were grade II. Trans-sphincteric fistulas were seen in 9 patients (28\%), 2 of them (6\%) were grade III and 7 fistulas (22\%) were grade IV. Two patients (6\%) had extra-sphincteric type. T2 weighted TSE, T2 TSE with fat suppression and T1 weighted fat suppressed post contrast sequences all show significant correlation with surgical results (with $p$-value less than 0.05 ) and the highest significance was obtained by the post contrast sequence ( $p$-value of 0.00001). The highest accuracy in the diagnosis of fistula in ano was with the use of T1 enhanced fat suppressed sequence (98.8\%) followed by $87 \%$ for the T2 fat suppression sequence and only $57 \%$ for the T2 weighted TSE sequence.

Conclusion $\quad \mathrm{MRI}$ is an essential, noninvasive tool in the preoperative assessment of perianal fistulous tracks, with the axial and coronal post contrast fat suppression T1 providing the highest accuracy and clinical significance with surgical data and therefore giving a highly promising decrement in the incidence of post-operative complications.

Keywords
Citation

MRI, perianal fistula

Jawad AM, kadhim MA, Al-Jobouri ZK, Hussain MAA. The value of magnetic resonance imaging in the evaluation of peri-anal fistula. Iraqi JMS. 2018; 16(2): 166-176. doi: 10.22578/IJMS.16.2.8
\end{abstract}

List of abbreviations: $\mathrm{CT}=$ Computed tomography, $\mathrm{MRI}=$ Magnetic resonance imaging, $\mathrm{STIR}=$ Short $\mathrm{T} 1$ inversion recovery, $\mathrm{TE}=$ Time to echo (Echo time), TR = Time to repeat (Repetition time), TSE = Turbo spin echo

\section{Introduction}

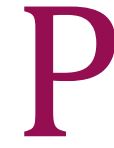
erianal fistula is an abnormal tract between an opening in the anal canal and the skin surface, and can result in significant morbidity. The prevalence of this condition is approximately 10 in 100,000, affecting males two to four times as frequently as females (1). Anorectal fistulas have been the subject of medical literature for over 2,500 years (2). The use of a seton (horsehair) in the treatment of anal fistulas was described by Hippocrates (3). Actually, the assessment of 
fistulous extension is the most important clinical indication for imaging in fistula in ano. This is due to the fact that the perianal fistula can affect the anal sphincter complex; the subsequent surgical intervention may result in impaired continence ${ }^{(4)}$. Therefore, identifying the relationship of the fistula to the anal sphincter is essential. It is also important to clarify the exact extensions of the fistulous tract and the presence or absence of associated abscesses, as missing them can lead to incomplete surgical management and thus leading to its recurrence, which is one of the main problems following surgery. Recurrence is inevitable if the internal opening was not correctly identified; this is because in such cases the original source of sepsis will not be eliminated, so identification of these parameters with proper imaging methods preoperatively will decrease the percentage of recurrence ${ }^{(5-8)}$.

In recent years, magnetic resonance imaging (MRI) has emerged as the leading imaging modality for preoperative classification of perianal fistulas. The first studies on cryptoglandular fistulas were performed with body-coil MRI and the true potential of MRI in detection of fistulas became evident ${ }^{(9,10)}$. MRI is now considered by many to be the gold standard in assessing and classifying anal fistulas and is equal or superior to examination under anesthesia (10-12). MRI provides accurate information on the anatomical plane in which the fistula is located as well as on the relationship between the fistula track and anal sphincters, pelvic floor and the levator ani muscle ${ }^{(13)}$, with accuracies reported up to $93 \%$ in classifying fistulas and $96 \%$ in delineating abscesses ${ }^{(14,15)}$. MRI examinations performed with body phased-array coils require no special patient preparation and are well tolerated. Advantages of the body phased-array coils include a larger field of view, which prevents fistula extensions from being overlooked. An important advantage of MRI is the multiplanar capability. The imaged volume should extend to the levators, include the whole presacral space and the entire perineum, which are common sites for extensions (16). Preoperative MRI has shown to reveal additional and clinically relevant information, thereby reducing recurrence rates after fistula surgery (9). MRI can be used to evaluate the activity of fistulas, which is a significant factor for determining the therapeutic strategy $(17,18)$. Although active fistulas appear hyperintense on T2-weighted images (T2WI), in some cases, hyperintensity of fistulas may be related to edema ${ }^{(19)}$. Increased enhancement on T1weighted images (T1WI), after intravenous administration of gadolinium-based contrast material, is generally considered indicative of active inflammation ${ }^{(19,20)}$. Theoretically higherfield-strength MRI provides a better signal-tonoise ratio, which can be used to achieve increased temporal resolution, decreased imaging time, and increased spatial resolution. The increased spatial resolution has the potential to improve lesion visibility, although comparative studies with $1.5-\mathrm{T}$ or $3.0-\mathrm{T}$ have not been reported on ${ }^{(21)}$.

\section{Classification of perianal fistula}

Two main classification systems are used in classifying and grading ano rectal fistula; the classification proposed by Parks et al. (22) in 1976, which was made for surgical use, and the St. James University Hospital classification (6), which was established based on MRI examination.

The aims of this study are to evaluate the role of MRI in the evaluation of perianal fistula and to show the value of using contrast enhanced MR study in the determination of the precise tract pathway, extensions and other associated pathologies. 
Table 1. Parks classification of anorectal fistula (22)

\begin{tabular}{cl}
\hline Type of fistula & \multicolumn{1}{c}{ Description } \\
\hline Inter-sphincteric & $\begin{array}{l}\text { Limited to intersphincteric plane, not piercing external sphincter or } \\
\text { levator muscles }\end{array}$ \\
Trans-sphincteric & $\begin{array}{l}\text { Passes through the external sphincter } \\
\text { Track courses upward within the intersphincteric plane to pass over }\end{array}$ \\
Supra-sphincteric & $\begin{array}{l}\text { Puborectalis muscles and descends through levator muscles to the } \\
\text { ischioanal fossa }\end{array}$ \\
Extra-sphincteric & Course is totally outside the external sphincter \\
\hline
\end{tabular}

Table 2. St. James University Hospital MRI classification system of perianal fistula (6)

\begin{tabular}{cl}
\hline Grade & \multicolumn{1}{c}{ Description } \\
\hline 1 & $\begin{array}{l}\text { Simple linear inter-sphincteric fistula } \\
\text { Intersphincteric fistula with intersphincteric abscess or secondary } \\
\text { fistulous track }\end{array}$ \\
3 & $\begin{array}{l}\text { Tran-sphincteric fistula } \\
\text { Trans-sphincteric fistula with abscess or secondary track within the } \\
\text { ischioanal or ischiorectal fossa } \\
5\end{array}$ \\
\hline
\end{tabular}

\section{Methods}

This cross sectional analytic study was conducted in the MRI Department of AlImamein Al-Kadhimein Medical City, Baghdad, Iraq during the period from November 2015 to December 2016. Forty-one patients with age range of 16-76 years with clinical suspicion of perianal fistula were referred from the surgical outpatient clinic. All of the patients presented with signs and symptoms of one or more of the following: perianal discharge, pain, perianal swelling and induration, they found to have one or more external openings during their clinical examination. Those patients were examined by MRI and 9 of them were excluded from this study because they showed no fistulous tracts ( 5 of them had pure peri-anal abscesses and 4 had peri-anal sinuses), the remaining 32 patients included in the study had perianal fistulas, they were 25 males and 7 females.

\section{Exclusion criteria}

No visible external orifice, patients with only perianal abscesses or sinuses, but had no evidence of fistula and patients with general contraindications for MRI (e.g. Patients with metallic shells or cardiac pacemakers and claustrophobic patients).

\section{Imaging technique}

All patients were evaluated by contrast enhanced pelvic MRI. The MRI examinations were performed with Achieva 3 Tesla MR Scanner Philips medical system, Netherland. Examination was performed using body surface coil, each patient was placed in a supine position. Distal rectum, anal canal, the internal and external sphincters, ischioanal fossa, levator muscle, supralevator space and the subcutaneous tissue in the perineal region 
were all included in the imaging volume. The following sequences were done for all patients: 1. T1 weighted fat suppression images in oblique axial and coronal planes with the following parameters: Repetition time (TR)= 400-600 mSec, Echo time (TE) $=5-10 \mathrm{mSec}$, slice thickness $(4-5 \mathrm{~mm})$ gap $(0.5-1 \mathrm{~mm})$, field of view $(370-430 \mathrm{~mm})$ and a flip angle of 90 degrees.

2. T2 weighted images with and without fat suppression in oblique axial and coronal planes with the following parameters: $T R=4000-5000$ $\mathrm{mSec}$, TE 100-130 mSec, slice thickness (4-5 $\mathrm{mm})$ gap $(0.5-1 \mathrm{~mm})$, field of view (370-430 $\mathrm{mm}$ ) and a flip angle of 90 degrees.

3. Repeated T1 weighted fat suppression images in oblique axial and coronal planes after intravenous manual injection of $0.1 \mathrm{mmol} / \mathrm{kg}$ body weight of gadolinium-based contrast agent.

Since the anal canal is tilted 45 degrees anteriorly in the sagittal plane so it was necessary to obtain oblique axial and coronal images that are oriented perpendiculars and parallel to the anal canal respectively. Therefore, we used a sagittal T2 single shot image with centerline along anal canal serving
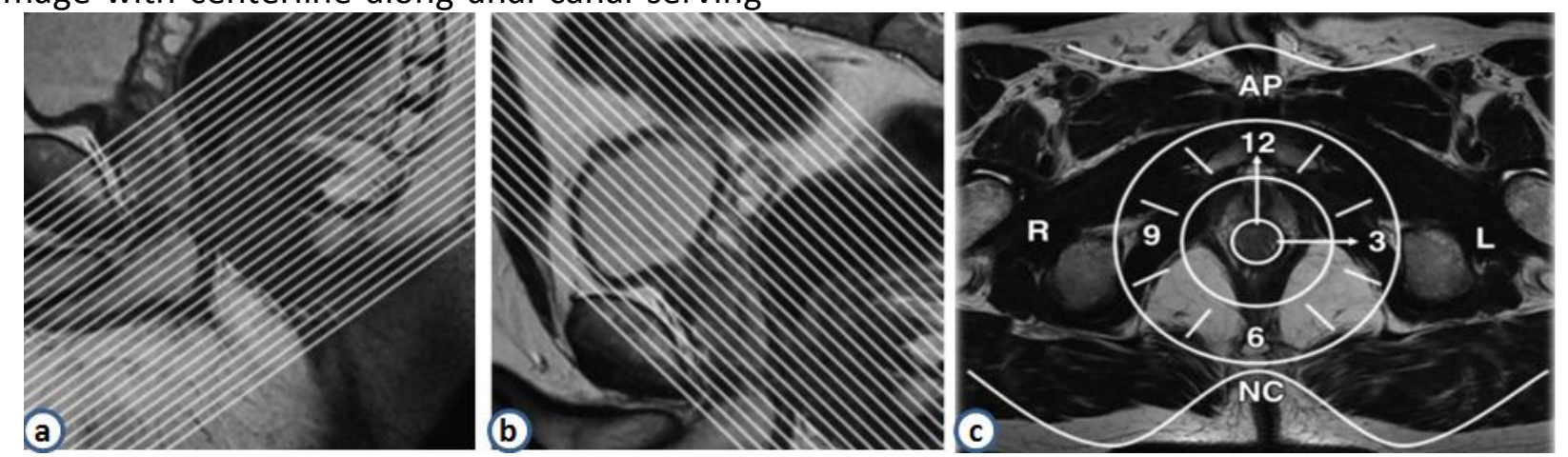

Figure 1. Single shot T2 weighted pelvic MRI sagittal section display the planning for acquisition of oblique axial (a) and oblique coronal (b) scans at an angle of 450 to the midline such that the images are orthogonal and parallel to the anal canal. (c) Axial T2-weighted MRI of the perineum showing the anal clock. NC = natal cleft, $A P=$ anterior perineum, $R=$ right aspect of the anal canal and $\mathrm{L}=$ left aspect of the anal canal ${ }^{(5)}$

The fistulous track was differentiated from abscess by using criteria of Laniado et al. ${ }^{(23)}$, in which fistulas were defined as being fluid filled tubular structures with a diameter smaller than $10 \mathrm{~mm}$ and abscesses were larger than $10 \mathrm{~mm}$. as a localizer for the subsequent sequences (figure $1 \mathrm{a}$ and $\mathrm{b}$ ).

\section{Image analysis}

The following parameters were evaluated with the mentioned MRI sequences: the type of the fistula, location of internal opening, associated abscesses and/or sinus tracts, horseshoe extension as well as any associated inflammatory changes. The type of the fistulous tract was analyzed and graded according to the St. James University Hospital MRI classification system (6). The transphincteric fistula was further sub classified into low or high levels according to the degree of involvement of the external sphincter (this is important because of different management between low and high levels fistula from the surgical point of view). In low type fistula, the lower third of the anal sphincter is involved while the involvement of the upper two thirds indicate a high fistulous type. The location of the internal opening was identified in the axial images using the anal clock as shown in figure $1 \mathrm{c}$.
Air pockets within the fluid collection favor abscesses. Horseshoe fistula was considered if it crosses the midline to the contralateral side. Surgical confirmation of the diagnosis was obtained for all the patients except two where 
the diagnosis was based on MRI results. Those 2 patients had extra sphincteric fistulas (they were known case of Crohn's disease). Surgery was not done for these 2 cases due to high risk of complications, therefore MR imaging characteristics and fixed anatomical landmarks were used in identifying and classifying these fistulas.

\section{Statistical analysis}

The collected data were tabulated and analyzed using Microsoft Excel 2010. The categorical data were presented as frequency and percentage tables. P-value was used to attain the significance of each MRI sequence in identifying perianal fistula and its associated findings in correlation to surgical results ( $p$ value less than 0.05 was considered a statistically significant correlation). Regression data analysis was used to calculate $p$-value for each MRI sequence. The overall accuracy rate was also calculated for each MRI sequence.

\section{Results}

Thirty-two patients had perianal fistulas confirmed by their MRI examinations and subsequent surgical results were included in this study, they were 25 males (78\%) and 7 females (22\%) with male: female ratio of 3.5:1. The most common type of fistula encountered was the inter-sphincteric type, it was seen in 21 patients (66\%) (16 fistulas (50\%) were grade I and 5 fistulas (16\%) were grade II). Transsphincteric fistulas were seen in 9 patients (28\%) ( 2 of them $(6 \%)$ were grade III and 7 fistulas (22\%) were grade IV, of all the transsphincteric type fistulas, 3 were low in type and 6 of them were high type fistulas). Two patients $(6 \%)$ had extra-sphincteric type (grade $\mathrm{V}$ according to MRI grading system). No suprasphincteric fistulas were encountered in this study. These findings were shown in fig. $2 \mathrm{~A}$ and B.

Associated abscesses were found in 10 cases and were all equally detected on $\mathrm{T} 2$ fat suppression and post contrast fat suppressed sequences with detection rates of $100 \%, 8$ of these 10 cases were seen on T2 TSE (80\%) and was detected on T1 TSE in 7 cases (70\%) only. Associated secondary tracts were seen in 11 cases, best detected by post contrast fat suppressed sequence (100\%). Approximately half of them were detected on T2 fat suppression (54\%), whereas only $27 \%$ and $18 \%$ was their detection rate on T2 TSE and T1 TSE.
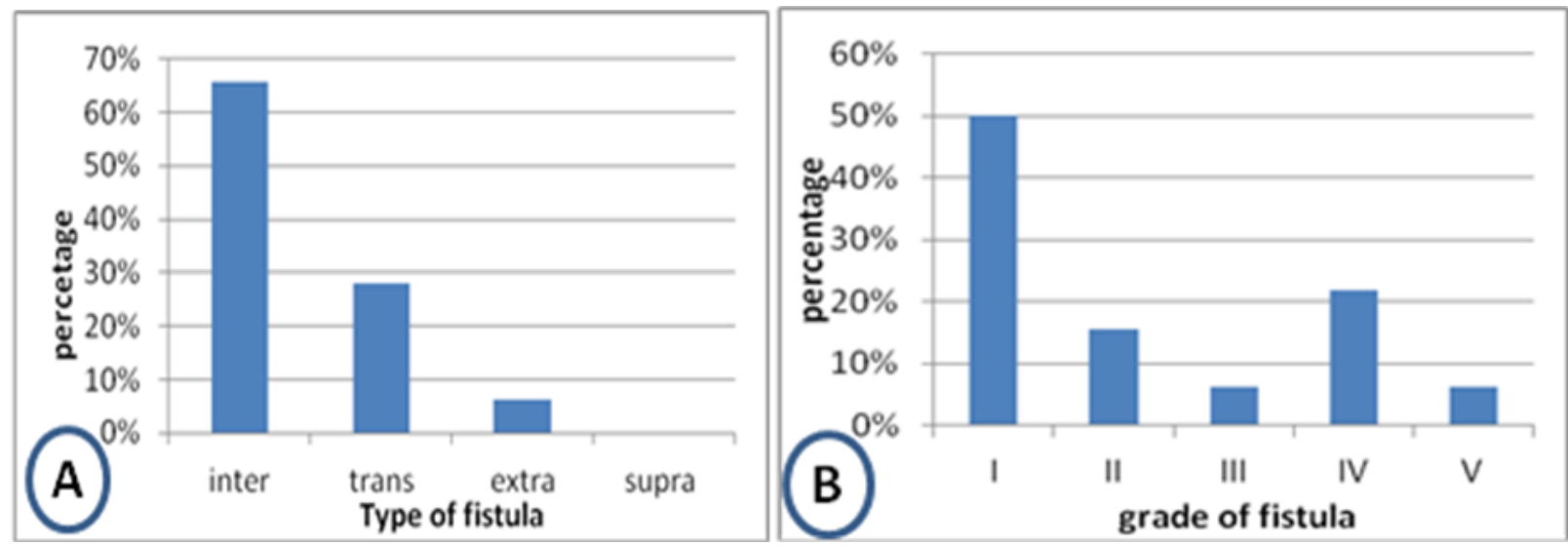

Figure 2. A: frequency and percentage of different types of perianal fistulas according to Parks classification. B: Frequency and Percentage of different grades of perianal fistula according to MRI grading system

The internal opening was seen in 29 patients and missed in 1 case that had been proven to be present according to surgical results later on. The two cases of the extrasphincteric type already do not have an internal opening as it bears no relationship to either of the 
sphincters or the anal canal. The internal openings were clearly depicted by post contrast fat suppression sequence $(96.6 \%)$, on T2 fat suppression sequence $(90 \%)$, less accurately seen by T2 TSE (56\%), and detected on T1 TSE in only (16.6\%). Most common locations were found to be at the 6 O'clock (in $48.2 \%$ of cases) followed by 5 o'clock in $13.7 \%$, as shown in table (3).

Table 3. Distribution of locations of internal opening on MRI axial images in patients with perianal fistula (No.=29)

\begin{tabular}{ccc}
\hline Location & No. of cases & Percentage \\
\hline 6 o'clock & 14 & 48.2 \\
$\mathbf{5}$ o'clock & 4 & 13.7 \\
$\mathbf{1 2}$ o'clock & 3 & 10.3 \\
$\mathbf{1}$ o'clock & 3 & 10.3 \\
$\mathbf{2}$ o'clock & 2 & 6.8 \\
$\mathbf{7}$ o'clock & 2 & 6.8 \\
8 o'clock & 1 & 3.4 \\
\hline Total & 29 & 100 \\
\hline
\end{tabular}

Horseshoe fistulous extension were seen in 3 cases and were all detected on post contrast fat suppression and T2 fat suppression (100\%), 2 of them were seen in T2 TSE (66.6\%) and only one-horse shoe extension was seen in T1 TSE (33.3\%).

Regression analysis was used to evaluate the significance of each MR sequence and $p$-value was obtained for each one of them. T1 TSE showed no significant correlation with the surgical results in depicting pathologies with a p-value of 0.169 and accuracy rate of $36 \%$; however, its role was important in demonstrating anatomy of the perianal region.
T2 TSE showed a significant correlation with a p-value of 0.007 , but it showed a diagnostic accuracy of $57 \%$. A more significant correlation was obtained by using $\mathrm{T} 2$ fat suppression axial and coronal sequences with a p-value of 0.001 and it showed accuracy rate of $87 \%$. The contrast enhanced axial and coronal fat suppressed T1 showed the strongest significance with the surgical results and revealed a $p$-value of 0.00001 and it had the highest accuracy rate of $98.8 \%$, as shown in table (4). Fig. 3, 4, 5 and 6 show some selected images from this study.

Table 4. Significance and accuracy rates of different MRI sequences in the depiction of perianal fistula and its associated findings in correlation with surgical results (No.=32)

\begin{tabular}{cccccc}
\hline Parameters & No. & T1 TSE & T2 TSE & T2 fat sat & T1 PC fat sat \\
\hline Primary tract & 32 & $16(50 \%)$ & $19(59 \%)$ & $29(90.6 \%)$ & $32(100 \%)$ \\
Associated abscesses & 10 & $7(70 \%)$ & $8(80 \%)$ & $10(100 \%)$ & $10(100 \%)$ \\
Secondary tract & 11 & $2(18 \%)$ & $3(27 \%)$ & $6(54.5 \%)$ & $11(100 \%)$ \\
Internal opening & 30 & $5(16.6 \%)$ & $17(56 \%)$ & $27(90 \%)$ & $29(96.6 \%)$ \\
Horseshoe extension & 3 & $1(33.3 \%)$ & $2(66.6 \%)$ & $3(100 \%)$ & $3(100 \%)$ \\
\hline P value & & 0.169 & 0.007 & 0.001 & 0.00001 \\
\hline Accuracy rate & & $36 \%$ & $57 \%$ & $87 \%$ & $98.8 \%$ \\
\hline
\end{tabular}



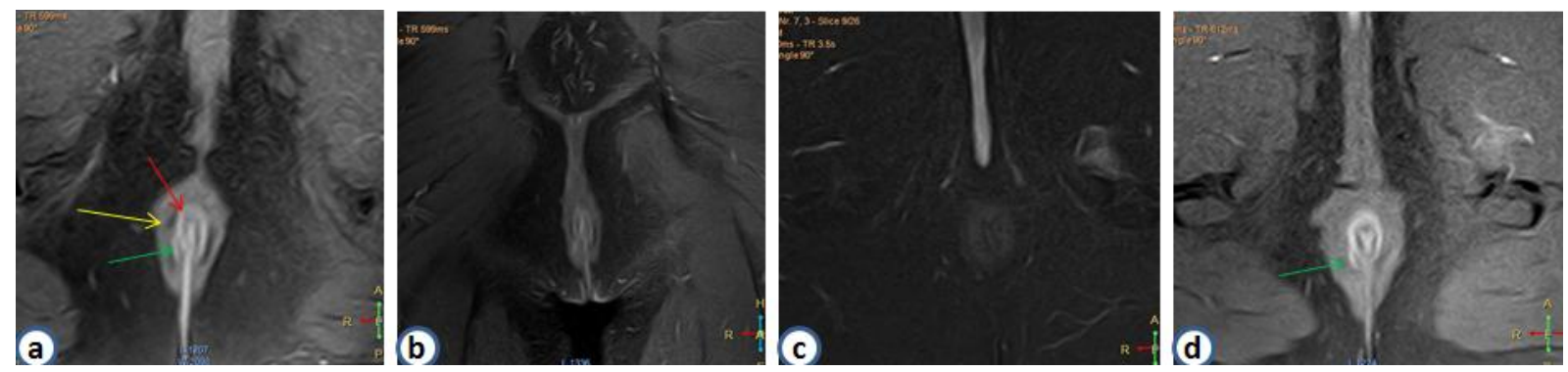

Figure 3. Axial (a) and coronal (b) fat suppressed PC T1 of 43 years old male presented with Rt. sided perianal discharge shows a grade I simple intersphincteric fistula (green arrow) with internal opening at 9 o'clock, the external (yellow arrow) and the internal (red arrow) anal sphincters. $C$ and $d$ are images of another $\mathbf{4 4}$ years old male patient presented with Rt. sided perianal discharge. A grade I intersphincteric fistula was not clearly depicted on the axial T2 fat suppression (c), but certainly seen on axial fat suppression PC T1 (d) (green arrow)
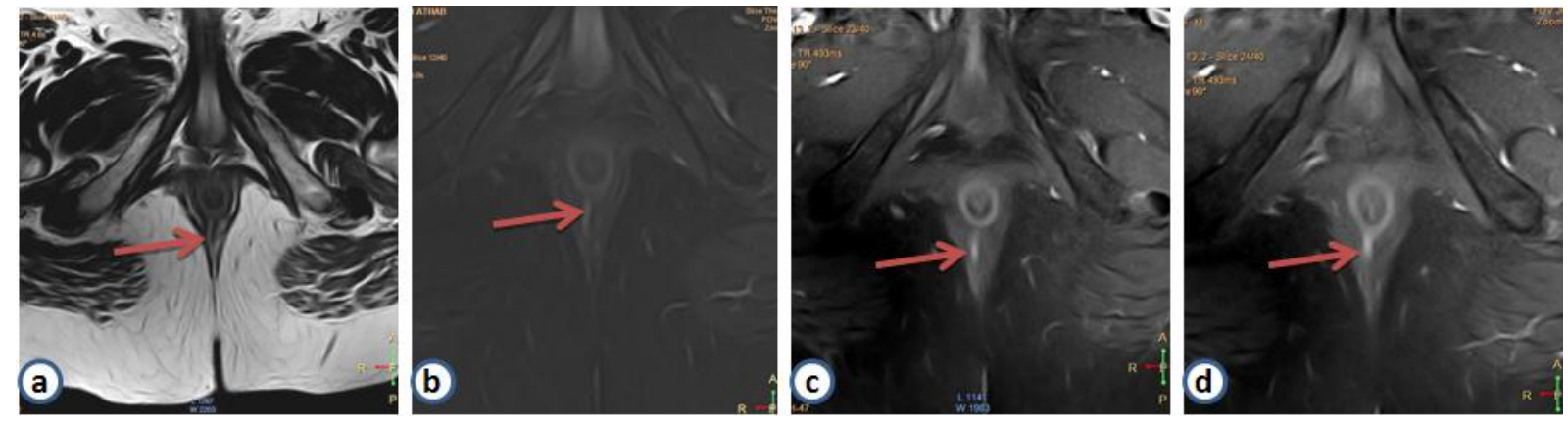

Figure 4. 38 years old male patient presented with signs and symptoms of perianal fistula. A grade III trans-sphincteric fistula (a) T2 axial, (b) T2 fat suppression axial, (c) and (d) T1 post contrast with fat suppression of the same patient showing a simple trans-sphincteric fistula

(arrow) with internal opening at 6 o'clock
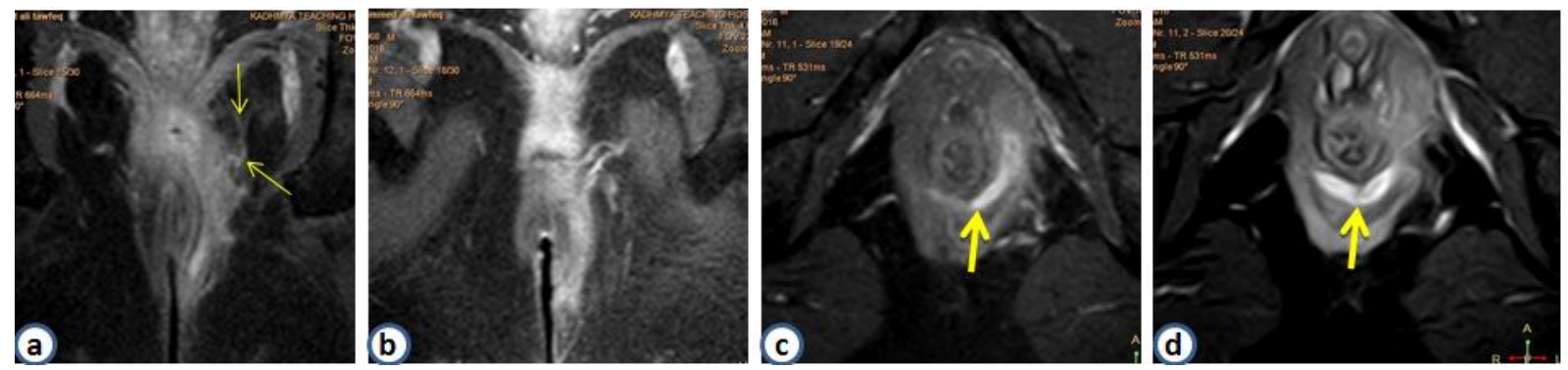

Figure 5. A 48 years old poorly controlled diabetic patient presented with left paramedian perianal discharge. (a-d) are coronal and axial contrast enhanced fat suppressed T1 showing a left sided high type tras-sphencteric fistula that crosses the midline (horseshoe extension "thick arrows") and showing two side branches (thin arrow) ... This was a grade IV fistula 

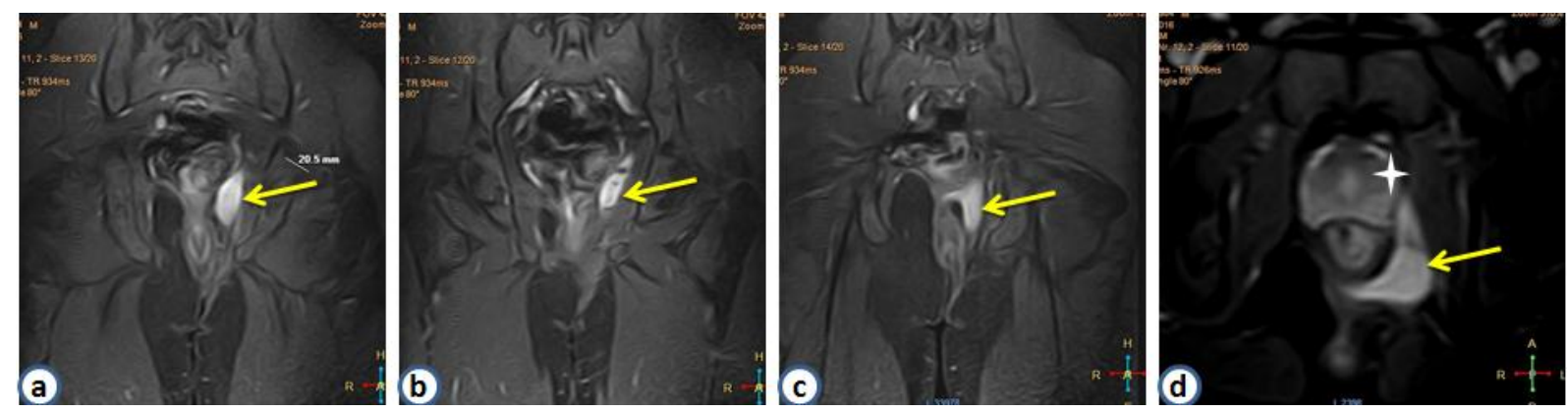

Figure 6. A 32 years patient who is a known case of crohn's disease showing a series of consecutive slices of coronal fat suppressed contrast enhanced T1 (a-c) and axial T1 enhanced fat suppressed sequence(d). There is a wide extrasphincteric fistulous tract (thick arrow) extending from the pelvis crossing the left levator anus muscle (star) and occupying the upper aspect of the ischioanal fossa, it also sends a side branch across the midline (horseshoe extension) and continues as abscess inferiorly (d). This was grade $\mathbf{V}$ fistula. There is enhancement of the wall of the lower rectum denoting associated proctitis

\section{Discussion}

The perianal fistulas have been described for centuries and were known to Hippocrates. This condition received more attention when Frederick Salmon started the St. Mark's Hospital in London in 1835, which was dedicated exclusively to patients suffering from perianal fistulas and other rectal diseases (13). Halligan et al. ${ }^{(19)}$ stated that the perianal fistula predominantly affects young adults, and males are more commonly involved than females. This was in agreement with the results of this study, which showed the mean age of the affected patients was 35 years with a male: female ratio of 3.5:1. Our results were also similar to those reported by Sainio et al. ${ }^{(1)}$ and Lunniss et al. (24).

According to Parks classification ${ }^{(22)}$, we found that the intersphincteric fistula was the most common type encountered, it was seen in 21 patients out of a total of $32(66 \%)$ and the trans-sphincteric fistula was the second most common type seen in 9 patients (28\%), these results were approximately similar to that of de Miguel Criado et al. ${ }^{(5)}$, their study were done 44 patients with fistulas, $60 \%$ were intersphincteric and 33\% were trans sphincteric in types. Moreover, we further characterized the trans sphincteric fistulas into high and low types according to the degree of involvement of external sphincter (25), this is important because of different management between high and low levels fistula, thus affecting patient's outcomes.

In this study, the grades of fistula were identified by using the St James's University Hospital classification. Grade I was the commonest category seen (50\%), this was higher than that of Mohamed et al. (26), which was $37.5 \%$ in their study, but was similar to Khan et al. (27) who found that grade I fistulas were also seen in $50 \%$. In contrast to Adurthy et al. (28) who found that type III was the most common and encountered in $46 \%$ in their study that included 26 patients and carried out in India, this difference may be attributed to the increased number of diabetic patients that led to more aggressive disease progression and later presentation.

The exact location of the primary tract whether in the ischioanal fossa or intersphincteric plane was most easily seen on axial images. The location of the internal opening according to the anal clock was also seen in this plane. We can differentiate trans-sphincteric from intersphincteric fistula by the presence or absence of external anal sphincter disruption. Coronal plane on the other hand is better in depiction of levator plane, thus allowing confident differentiation of supralevator from infralevator extension of the fistulas. Therefore, both axial and coronal sequences are required to provide all the important 
details needed. These were also in agreement with the findings of Stoker et al. (29).

Associated perianal abscesses were found in 10 cases and were all equally detected on T2 fat suppression and post contrast fat suppressed sequences with detection rates of $100 \%$. This finding was in agreement to what had been obtained by Mohamed et al. (26) with detection rates of $100 \%$ in these sequences. Regarding the associated peri-anal secondary tracts, they were seen in 11 cases, best detected by post contrast fat suppressed sequence (100\%). This was comparable to the findings of Mohamed et al. (26) and Khan et al. (27) in which their detection rates were $100 \%$ and $94.4 \%$ respectively. It has been shown that MRI is more successful at showing secondary tracks than both digital examination and surgery ${ }^{(29)}$.

Concerning the internal opening detection, out of 30 patients studied, the internal opening was seen in 29 patients and missed in 1 patient, which was evident during subsequent surgery, this may be attributed to the various anatomical or functional conditions such as small or narrow opening or it may be intermittently closed at the time of MRI examination. Similar findings were seen in a previous study done by Yildirim et al. ${ }^{(30)}$, three internal openings were missed in their study which was performed on 26 patients.

The detection rate of the internal opening in this study was $96 \%$ on fat suppressed post contrast $\mathrm{T} 1$ and $90 \%$ on $\mathrm{T} 2$ fat suppressed sequence, These findings were comparable to that of Singh et al. (31), 46 internal openings were accurately detected out of 48 Cases (detection rate of $96 \%$ on fat suppressed enhanced T1), our results were also close to that of Mohamed et al. ${ }^{(26)}$ where the detection rates in were $100 \%$ and $91 \%$ on T1 enhanced fat suppression and $\mathrm{T} 2$ fat suppression sequences respectively, however our detection rate and was slightly lower than the results of Khan et al. (27) where the detection rates was $100 \%$ on T1 post contrast sequences. We found that the most common location of the internal opening was in the region of $60^{\prime}$ clock (seen in $48 \%$ ), this was slightly lower than that seen by Mohamed et al. (26) $(50 \%)$ and Yildirim et al. (30) (57\%).
Horseshoe fistulous extension were seen in 3 cases and were all detected on post contrast fat suppressed $\mathrm{T} 1$ and $\mathrm{T} 2$ fat suppression sequences with a detection rate of $100 \%$ in each sequence, this was identical to the results obtained by Yildirim et al. ${ }^{(30)}$. (Detection rates of $100 \%$ in each sequence) and Mohamed et al. (26) (with detection rates of $95 \%$ in T2 fat suppression and $100 \%$ in fat suppressed enhanced T1).

We had seen that T2 fat suppression and T1 fat suppressed enhanced image had exactly the same detection rate $(100 \%)$ regarding recognition of peri-anal abscesses and track horseshoe extensions, these results were similar to that of Singh et al. (31) were the detection rate was $100 \%$ for both parameters. Our results were also comparable to the results of Mohamed et al. (26) where both sequences were equally $(100 \%)$ detect peri-anal abscesses, but there was slight increase in the detection of horseshoe extension seen with enhanced fat suppressed T1 compared with the T2 fat suppression sequence. However, we had concluded that T1 fat suppressed enhanced sequences had higher detection rate than T2 fat suppressed images regarding primary tracts, secondary extensions and internal openings, but still both sequences gave significant correlation with surgical results with $p$-values of less than 0.05. However, the accuracy rate of the T2 fat suppressed sequence was $87 \%$ in contrast to the $98 \%$ achieved by the post contrast sequence. The post contrast study was even more significant than fat suppressed T2 ( $p$-values of 0.00001 and 0.001 respectively). These were in agreement with the study of Mohamed et al. (26) who attained a significant correlation for these two sequences (with a $p$ values of less than 0.05) and even higher significance in using contrast MRI (with a p-value of less than 0.001). Their results showed a diagnostic accuracy of $99.4 \%$ for post contrast fat suppressed T1 TSE. Our results were also comparable to the results of Mazroa et al. (32) and Daabis et al. ${ }^{(33)}$, they found the diagnostic accuracy of post contrast sequence in the detection of perianal fistula to be $97.3 \%$ and $95 \%$ respectively. 
Finally, this study had shown that the T2 fat suppression had no added diagnostic information to that shown by the contrast enhanced MR imaging. This was in agreement with the results of Spencer et al. (20), however radiologists who are not routinely deal with $M R$ interpretations of peri-anal fistulas, may benefit from both sequences in interpreting their data.

This study concluded that MRI is an essential, noninvasive tool in the preoperative assessment of perianal fistulous tracks and clarifying the presence or absence of other associated complications. Using St James's University Hospital MRI-based grading system provides more detailed information regarding the primary track as well as its secondary extensions and associated abscesses. This will help in deciding the suitable way of management and hence decreasing the incidence of recurrence and improving the patients' outcome. Axial and coronal contrast enhanced fat suppressed T1 showed highly significant and accurate correlation with surgical findings and was superior to other MRI sequences in showing hidden tracks and internal orifice locations.

\section{Acknowledgments}

Deep thanks to the great operators at the MRI department of Al-Imamein Al-kadhimein Medical City for their collaboration and technical help provision. Great thanks to all patients who agreed to participate in this study.

\section{Authors contribution}

Dr. Kadhim: conception and design, interpretation of results. Dr. Jawad: collection of data, assembly and interpretation of results, manuscript writing. Dr. Al-Jobouri: participation in data collection and statistical analysis. Hussain: Arranging the protocols for the MRI examinations. All authors have approved the final article.

\section{Conflict of interest}

Authors declare no conflict of interests.

\section{Funding}

No external funding sources.

\section{References}

1. Sainio P. Fistula-in-ano in a defined population. Incidence and epidemiological aspects. Ann Chir Gynaecol. 1984; 73(4): 219-24.

2. Nelson RL, Abcarian H. Epidemiology, incidence and prevalence of fistula in ano. In: Abcarian H. (ed). Anal fistula. New York: Springer Science \& Business Media; 2014. p. 1-7. doi: 10.1007/978-1-4614-9014-2_1.

3. Corman ML. Classic articles in colon and rectal surgery. Hippocrates: on fistulae. Dis Colon Rectum. 1980; 23(1): 56-9.

4. Lewis RT, Bleier Jl. Surgical treatment of anorectal crohn disease. Clin Colon Rectal Surg. 2013; 26(2): 90-9. doi: 10.1055/s-0033-1348047.

5. de Miguel Criado J, del Salto LG, Rivas PF, et al. MR imaging evaluation of perianal fistulas: spectrum of imaging features. Radiographics. 2012; 32(1): 175-94. doi: 10.1148/rg.321115040.

6. Morris J, Spencer JA, Ambrose NS. MR imaging classification of perianal fistulas and its implications for patient management Radiographics. 2000; 20(3): 623-35; discussion 635-7. doi: 10.1148/radiographics.20.3.g00mc15623.

7. Ziech M, Felt-Bersma R, Stoker J. Imaging of perianal fistulas. Clinical gastroenterology and hepatology. 2009; 7(10): 1037-45. doi: 10.1016/j.cgh.2009.06.030.

8. Kim Y, Park YJ. Three-dimensional endoanal ultrasonographic assessment of an anal fistula with and without $\mathrm{H}(2) \mathrm{O}(2)$ enhancement. World J Gastroenterol. 2009; 15(38): 4810-5.

9. Buchanan $\mathrm{GN}$, Halligan $\mathrm{S}$, Bartram $\mathrm{Cl}$, et al. Clinical examination, endosonography, and $\mathrm{MR}$ imaging in preoperative assessment of fistula in ano: comparison with outcome-based reference standard. Radiology. 2004; 233(3): 674-81. doi: 10.1148/radiol.2333031724.

10. Lunniss PJ, Armstrong P, Barker PG, et al. Magnetic resonance imaging of anal fistulae. Lancet. 1992; 340(8816): 394-6. doi: 10.1016/0140-6736(92)91472$\mathrm{K}$.

11. Berman L, Israel GM, McCarthy SM, et al. Utility of magnetic resonance imaging in anorectal disease. World J Gastroenterol. 2007; 13(23): 3153-8. doi: 10.3748/wjg.v13.i23.3153.

12. Buchanan G, Halligan S, Williams $A$, et al. Effect of MRI on clinical outcome of recurrent fistula-in-ano. Lancet. 2002; 360(9346): 1661-2. doi: 10.1016/S0140-6736(02)11605-9.

13. Chauhan NS, Sood D, Shukla A. Magnetic Resonance Imaging (MRI) characterization of perianal fistulous disease in a rural based tertiary hospital of North India. Pol J Radiol. 2016; 81: 611-7. doi: 10.12659/PJR.899315.

14. Beets-Tan RG, Beets $G L$, van der Hoop $A G$, et al. Preoperative MR imaging of anal fistulas: does it 
really help the surgeon? Radiology. 2001; 218(1): 7584. doi: 10.1148/radiology.218.1.r01dc0575.

15. Panes J, Bouhnik Y, Reinisch W, et al. Imaging techniques for assessment of inflammatory bowel disease: joint ECCO and ESGAR evidence-based consensus guidelines. J Crohn's Colitis. 2013; 7(7): 556-85. doi: 10.1016/j.crohns.2013.02.020.

16. Baskan O, Koplay M, Sivri M, et al. Our experience with MR imaging of perianal fistulas. Pol J Radiol. 2014; 79: 490-7. doi: 10.12659/PJR.892098.

17. Yoshizako T, Wada A, Takahara $T$, et al. Diffusionweighted MRI for evaluating perianal fistula activity: feasibility study. Eur J Radiol. 2012; 81(9): 2049-53. doi: 10.1016/j.ejrad.2011.06.052.

18. Yoshizako T, Kitagaki H. A pictorial review of the impact of adding diffusion-weighted MR imaging to other MR sequences for assessment of anal fistulae. Jpn J Radiol. 2013; 31(6): 371-6. doi: 10.1007/s11604013-0204-x.

19. Halligan S, Stoker J. Imaging of fistula in ano. Radiology. 2006; 239(1): 18-33. doi: 10.1148/radiol.2391041043.

20. Spencer JA, Ward J, Beckingham IJ, et al. Dynamic contrast-enhanced MR imaging of perianal fistulas. AJR Am J Roentgenol. 1996; 167(3): 735-41. doi: 10.2214/ajr.167.3.8751692.

21. Sahni VA, Ahmad R, Burling D. Which method is best for imaging of perianal fistula? Abdom Imaging. 2008; 33(1): 26-30. doi: 10.1007/s00261-007-9309-y.

22. Parks AG, Gordon $P H$, Hardcastle JD. A classification of fistula-in-ano. Br J Surg. 1976; 63(1): 1-12.

23. Laniado $M$, Makowiec F, Dammann F, et al. Perianal complications of Crohn disease: MR imaging findings. Eur Radiol. 1997; 7(7): 1035-42. doi: 10.1007/s003300050248.

24. Lunniss PJ, Jenkins PJ, Besser GM, et al. Gender differences in incidence of idiopathic fistula-in-ano are not explained by circulating sex hormones. Int J Colorectal Dis. 1995; 10(1): 25-8. doi: 10.1007/BF00337582.

25. van Koperen PJ, Bemelman WA, Bossuyt PM, et al. The anal fistula plug versus the mucosal advancement flap for the treatment of anorectal fistula (PLUG trial). BMC surgery. 2008; 8(1): 11. doi: 10.1186/1471-2482-8-11.

26. Mohamed RE, Abo-Sheisha DM. Role of magnetic resonance imaging in pre-operative assessment of ano-rectal fistula. Egyptian J Radiol Nucl Med. 2014; 45(1): 35-47. doi: 10.1016/j.ejrnm.2013.10.008.

27. Khan $S$, Sharief $S A$, Ahmed $M$, et al. Cross sectional study of MR fistulography in the evaluation of perianal fistulae and its surgical correlation. Al Ameen J Med Sci. 2015; 8(4): 299-304.

28. Adurthy $P$, Prabhu SD, Kumar $A$. MRI in assessment of perianal fistula. Indian J Applied Res. 2016; 6(1): 5023.

29. Stoker J, Rociu E, Wiersma TG, et al. Imaging of anorectal disease. British J Surg. 2000; 87(1): 10-27. doi: 10.1046/j.1365-2168.2000.01338.x.

30. Yildirim N, Gökalp G, Öztürk $E$, et al. Ideal combination of MRI sequences for perianal fistula classification and the evaluation of additional findings for readers with varying levels of experience. Diagn Interv Radiol. 2012; 18(1): 11-9. doi: 10.4261/1305-3825.DIR.4092-10.1.

31. Singh K, Singh N, Thukral CL, at al. Magnetic resonance imaging (MRI) evaluation of perianal fistulae with surgical correlation. J Clin Diagn Res. 2014; 8(6): RC01-4. doi: 10.7860/JCDR/2014/7328.4417.

32. Mazroa JA, Elmogy SA, Elgendy MM. Value of contrast enhanced spoiled gradient (SPGR) MR and MIP MR imaging in diagnosis of peri-anal fistula. Egyptian J Radiol Nucl Med. 2012; 43(2): 119-28. doi: 10.1016/j.ejrnm.2012.01.004.

33. Daabis N, El Shafey R, Zakaria $Y$, et al. Magnetic resonance imaging evaluation of perianal fistula. Egyptian J Radiol Nucl Med. 2013; 44(4): 705-11. doi: 10.1016/j.ejrnm.2013.09.003.

\section{Correspondence to dr Mohammed A. kadhim E-mail: dr_a_mohammed@yahoo.com mohammedal-jiboori@colmed-alnahrain.edu.iq Received Jul. $5^{\text {th }} 2017$ Accepted Dec. $28^{\text {th }} 2017$}

